\title{
Governance, management and performance in public networks: How to be successful in shared-governance networks
}

\author{
Daniela Cristofoli · Josip Markovic • \\ Marco Meneguzzo
}

Published online: 9 October 2012

(C) Springer Science+Business Media New York 2012

\begin{abstract}
This paper compares four cases and explores the effects on network performance of network governance, coordination mechanisms, and the abilities of the network manager. The focus is on shared-governance networks, which are in general considered to have difficulties achieving high-level performances. The cross-case comparison suggests a relationship between coordination mechanisms and the way shared-governance networks are managed: in order to be successful, they must be able to rely on formalized mechanisms and make a pool of "network administrators" responsible for their governance.
\end{abstract}

Keywords Public networks · Governance · Management · Performance · Collaboration

\section{Introduction}

Scholars only started focusing on network governance methods and exploring their relationships with network performance relatively recently. It was in 2008 that the well-known article "Modes of network governance. Structures, management and

\section{Cristofoli (两) J J. Markovic}

Faculty of Economics, Università della Svizzera Italiana, Lugano, Switzerland e-mail: daniela.cristofoli@usi.ch

\section{J. Markovic}

e-mail: josip.markovic@usi.ch

\section{Meneguzzo}

Department of Business, Government and Philosophy, University of Rome Tor Vergata, Rome, Italy e-mail: meneguzzo@economia.uniroma2.it 
effectiveness" by Provan and Kenis (2008) identified three different forms of network governance: Shared/Participant governance, Lead Organization governance and Network Administrative Organization (NAO) governance. In a subsequent article, the authors looked in more detail into the relationships between these governance forms and network performance, arguing that the appropriateness and success of different governance forms can vary in different circumstances (Kenis and Provan 2009). Shared-governance forms in particular are normally considered to have difficulties achieving high-level performances. They are only expected to work well in small, geographically concentrated networks where full, active face-toface interaction between network members is possible (Kenis and Provan 2009).

Our paper aims to contribute to the literature on the topic. Following the lead of Kenis and Provan (2009), it will focus on shared-governance networks and examine the key factors in making them successful. "How to be successful in sharedgovernance networks" is the central research issue in our study.

We took the literature on service-delivery networks as our theoretical framework (Turrini et al. 2010) and identified two categories of predictors of network performance: network-coordination mechanisms and the abilities of the network manager. We then explored whether coordination mechanisms and managerial abilities, or a combination of them, can lead to success for shared-governance networks.

Public homecare-assistance networks in Switzerland provided the empirical setting for our study. In keeping with the purposes of our analysis, we conducted a multiple case study based on four networks with shared governance.

The study results show that when many players are involved in network governance, good performances are only possible if a well-defined set of rules and procedures are supervised by a group of network "administrators" (as better defined later).

Our study makes contributions on both a theoretical and a managerial level. In theoretical terms, firstly it explores the relationship between network success and different governance structures. The results show that coordination mechanisms and managerial abilities do play a crucial part in the success of shared governance network, regardless of circumstances like network size and geographical concentration. Secondly, our study follows the direction suggested by Turrini et al. (2010) and sheds light on the effects of interaction among the predictors of the network performance. The results allow us to suppose that interaction between coordination mechanisms and managerial abilities leads to network success. Thirdly, our study complements the existing studies on the roles and abilities of the network manager. The results reveal that in some circumstances, network success may not be reliant on a network manager, or perhaps a different role and managerial abilities more similar to those of an impartial administrator might be preferable. Fourthly, our paper casts new light on the management-bureaucracy dichotomy in public networks. The results seem to suggest that as network governance becomes more complex and the degree of sharing among multiple players increases, it becomes more and more preferable to comply with existing rules and procedures administered by impartial institutional bodies. From a managerial point of view, 
the results of our study seem, thus, to suggest that administering shared-governance networks in a bureaucratic way is one of the keys to making them successful.

The paper is divided into four sections. The first one gives an overview of network governance methods and discusses the peculiarities of shared-governance networks. The second section reviews the concepts of coordination mechanisms and managerial abilities and presents the theoretical framework of the paper. The third section describes the study method and presents the empirical setting. The last section describes and discusses the results of the study.

\section{Methods of network governance}

In a number of articles in 2008 and 2009, Provan and Kenis (2008) and Kenis and Provan (2009) began to shift their focus from the structural characteristics of public networks (Provan and Milward 1995; Provan and Sebastian 1998; Provan et al. 2005) towards the distribution of governance power within the network structures, while showing that different network-governance configurations can give different results in terms of network performance.

The simplest governance form that a network can take is joint governance by the participants. These shared-governance networks (or participant-governed networks) consist of multiple organizations that work collectively as a network (without any distinct governance entity), making all of the decisions and managing network activities by themselves. The strength of these networks lies in the involvement of all network partners and in their flexibility and responsiveness to the needs of the network participants. However, a structure of this kind has a negative impact on network efficiency (ibid.). Accordingly, it is more appropriate in small, geographically concentrated networks where full, active face-to-face interaction between network members is possible.

The second network form, the Lead Organization-governed network, is based on the coordination of activities and key decisions by a Lead Organization. This organization provides administration for the network and facilitates the work of partner organizations as they seek to achieve network goals (ibid.). The advantages of this model lie in increased efficiency through easier coordination of network activities and the legitimacy provided by the Lead Organization (ibid.). The weakness is that the Lead Organizations often have their own agenda. This can create tension between the Lead Organization and network partners due to their different organizational interests (ibid.). This model is common in vertical relationships between buyers and suppliers or between funders and recipients. It can also occur in horizontal multilateral networks, most often when one key organization has sufficient resources and legitimacy to play a leading role.

The third network form is the NAO model. It is based on the idea of a separate administrative entity which manages and coordinates the network and its activities just like a Lead Organization, but without being a network partner. Instead, it provides its services to the network clients. This structure allows network organizations to interact and work together while the main activities and key decisions are coordinated by a separate, independent entity (Kenis and Provan 
2009). The NAO, which can be a government entity or a non-profit organization, will be established with the express purpose of governing the network. These organizations may have relatively informal structures revolving around single individuals who act as network facilitators or brokers, or they may be more formalized and complex organizations with a board and a management team. According to Kenis and Provan (2009), the second, more formalized approach is very likely to be used when the NAO is seeking official recognition to boost its legitimacy among internal and external stakeholders (ibid.). The strengths of this governance model are its greater legitimacy, sustainability and efficiency, while its weakness lies in its bureaucratic decision-making process (ibid.). NAO governance forms tend to be more suitable for large, highly complex networks.

The abovementioned considerations make it seem apparent that shared-governance networks are the simplest governance form, but they appear to have more difficulties achieving high-level performances. "How to be successful in sharedgovernance networks" is the research issue that we will try to address.

\section{Theoretical framework}

The existing literature provides us with a number of predictors of network performance, ranging from the mechanisms for the coordination of the network partners, to the abilities that the network manager must have in order to run the network successfully. According to some authors (for example, see Turrini et al. 2010), it seems likely that these factors can have a joint effect on network performance. In the following section, we will review the existing studies on coordination mechanisms and the abilities of the network managers in successful networks, while also presenting the theoretical framework behind our study (Fig. 1).

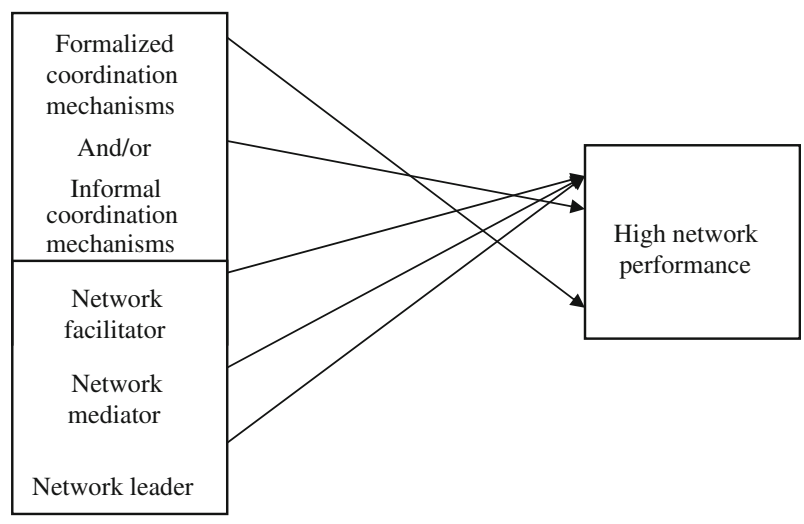

Fig. 1 Theoretical framework 


\subsection{Coordination mechanisms in successful networks}

Many studies have shown that network performance can be boosted by formalized coordination mechanisms such as: joint information and communication systems; shared marketing, planning or implementation structures; joint staff activities; integrated service capacities (e.g. a one-stop entity at the service of network clients); organization of meetings; definition of the network agenda; the establishment of ground rules and laying down rules for decision-making (Gray 1989; Kljin 1996; Jennings and Ewalt 1998; Provan and Sebastian 1998; Shortell et al. 2002; Conrad et al. 2003; Bazzoli et al. 2003). In public networks for the provision of health and social services, some of the specific coordination mechanisms that have been successfully introduced include case management, project management systems for ongoing care, peer review systems and continuous quality improvement systems.

Personal and informal contact between network partners based on long-lasting relationships and a high degree of trust has also been shown to have a positive impact on network performance. The degree of trust is mentioned by many scholars as a crucial factor that influences relationships within a network and therefore the network performance, including Ferlie and Pettigrew (1996), and Provan and Kenis (2008).

\subsection{Abilities of the network manager in successful networks}

As public network literature gradually developed, scholars left behind the focus on network structure and mechanisms and started to concentrate on the abilities of the network manager as predictors of network performance, in the belief that managerial skills have an impact on network performance (Kickert et al. 1997; Agranoff and McGuire 2001; Mandell 2001; Huang and Provan 2007; Meier and O'Toole 2001) and that in some cases they play an even bigger part than the network structure and mechanisms (Kort and Klijn 2011).

Generally speaking, public network management abilities can be split into two broad categories: nurturing the network and steering it. Abilities of the former kind are typical of network "facilitators" and "mediators", while those of the latter kind are associated with network "leaders" (Agranoff and McGuire 2001, 2003; McGuire 2002).

In order to nurture the network, the network facilitator/mediator is expected to be able to foster an environment for a good partner interaction (by creating an institutional building and establishing working rules to govern partner participation), promote information exchanges between network partners, maintain harmony and develop ways to cope with strategic and operational complexity (Kickert et al. 1997; Agranoff and McGuire 2001; O’Toole and Meier 2004). On top of all this, the facilitator/mediator must be able to ease tension among network members in order to strengthen their partnerships. This can be done by seeking formal arrangements through bargaining and negotiations, by reorganizing the network's structural processes and by creating governance mechanisms which align the interests of the partner organizations (Kickert et al. 1997). Ultimately, the network facilitator/ mediator is expected to be able to build commitment to the mission and the goals of 
the network not only among network members but also among external stakeholders (Agranoff and McGuire 2001). When it comes to steering the network, the network leader is expected to be able to perform three different tasks: action planning, activating and re-planning. Action planning consists of establishing clear missions and developing focused strategies and measures for the network and for the organization in which the leader works (Agranoff and McGuire 1998; Mitchell et al. 2002). Activating consists of selecting the appropriate players and resources for the network (Mitchell and Shortell 2000; Agranoff and McGuire 2001, 2003), tapping the skills, knowledge and resources of others, gaining trust and building consensus (Agranoff and McGuire 2001). "Re-planning" consists of altering and repositioning the network objectives when important changes occur in the network environment (Shortell et al. 2002).

\section{Method}

On the basis of the abovementioned theoretical framework, our paper aims to explore whether good performances in shared-governance networks are a result of coordination mechanisms, the abilities of the network manager, or a specific combination of coordination mechanisms and managerial abilities.

Due to the exploratory nature of the project, we conducted a multiple case study (Yin 1984).

\subsection{Empirical setting}

Public homecare service networks in Switzerland provided the empirical setting for our study.

We chose Switzerland because it is an information-rich case as far as collaboration between public, private and non-profit organizations is concerned (Steiner 2000, 2003). Due to the small size of the Swiss municipalities (only ten of the 2,516 municipalities have more than 50,000 inhabitants), collaboration for the provision of public services is in fact a popular approach in the country: more than $60 \%$ of the Swiss municipalities are involved in networks for the joint provision of public services (Steiner 2000, 2003). We chose, then, homecare networks because collaboration is most widespread in the health and social field, with $69 \%$ of the Swiss municipalities involved in networks of this kind (Steiner 2000, 2003).

In early 2000, a federal law (which was followed by a series of cantonal laws) was issued to induce Swiss municipalities to collaborate when providing health and social care services at home for the elderly, young families, single parents, disabled persons or other groups that struggle to cope with their everyday routines. As a result, "Spitex organizations" were formed (in the form of consortia, foundations or associations promoted by Swiss Cantons and/or municipalities) to provide services and support to citizens who need medical aid, care, supervision, monitoring or advice to increase their capacity for living at home.

Spitex organizations tend to provide some services by themselves and activate other non-profit organizations to provide ancillary services (such as the 
transportation of disabled clients, meal services for those who are unable to cook, night-time care, oncological care and psychological support), thus creating a network of organizations that jointly cater to patients' needs (hereinafter we will refer to them as Spitex networks).

The idea behind Spitex networks is that patients should be treated, supported and advised by specially trained nurses in a familiar environment, so as to increase their comfort, autonomy and self-determination. Furthermore, providing these services in the patient's home is considered to be less cost-intensive than treatment in stationary facilities like hospitals or nursing homes. These advantages make the homecare services provided into an essential part of the Swiss health and social care system.

According to the Swiss Federal Statistical Office (FSO), at present there are around 575 publicly entrusted Spitex organizations in Switzerland. 540 of them are in 19 German-speaking cantons with 1,585 municipalities and 5.5 million inhabitants. A further 1,024 municipalities and 2.4 million inhabitants are covered by 30 organizations in 6 French-speaking cantons and 6 in the Italian speaking canton (Swiss Federal Statistical Office 2010). In 2009, Spitex networks served 214,000 patients. 147,000 of them were female $(69 \%)$ and the vast majority $(75 \%)$ of patients were older than 64 years of age (ibid.). The total number of patients amounted to $2.8 \%$ of the Swiss population (ibid.). Spitex networks were able to provide this $2.8 \%$ of the Swiss population who need social and health care assistance with services in their homes, meaning that it was not necessary for them to be treated in stationary facilities like hospitals or nursing homes.

Spitex networks tend to have a variety of structures and forms of governance, as our previous paper shows (Cristofoli et al. 2011a, b). In addition to networks with a Lead Spitex Organization that either provides homecare services or activates and coordinates the network partners, there are networks in which the governance is shared among all-or most—of the network partners.

This makes Switzerland an interesting empirical setting for a focus on sharedgovernance networks and exploration of the factors in their success.

\subsection{Case selection}

In order to conduct our analysis, we selected four cases using the following criteria (Table 1): (1) four shared-governance networks; (2) two successful and two unsuccessful networks; (3) two larger and two smaller networks; (4) two networks operating in concentrated geographical areas and two networks operating in more

Table 1 Case selection

\begin{tabular}{lll}
\hline & Geographical concentration & Geographical dispersion \\
\hline Larger networks & Spitex-Blu (23) & Spitex-Indigo (70) \\
Smaller networks & Spitex-Violet (13) & Spitex-Grey (16) \\
\hline
\end{tabular}

Bold for successful networks

The number of network partners is given in brackets 
widespread areas. This research design allowed us to investigate the impact of coordination mechanisms and managerial abilities on network performance by cross-checking them with the network size and geographical concentration, which are key factors behind the success of shared-governance networks according to the existing literature (Kenis and Provan 2009). On top of this, all four networks are mandated and have existed for around ten years. This meant that there was no variation in the "exogenous factors" which Provan and Kenis (2008) and Kenis and Provan (2009) claim can affect network performance. In order to guarantee the anonymity of the selected networks, we will label them as Spitex-Blu, SpitexIndigo, Spitex-Violet and Spitex-Grey. There will be a shorter description of SpitexIndigo than the other networks because it has already been described in a previous paper.

The Spitex-Blu network is built around a non-profit association which was set up to deliver home and social care services to the people of one municipality (geographical concentration). It is entrusted with the responsibility of providing homecare assistance by the municipality and when necessary it activates non-profit organizations to provide complementary services. The resulting network is made up of approximately 23 partners (network size $=23$ partners). The most important partners-including the municipality, the Spitex organization, and major non-profit organizations-have established an inner circle which governs the network through mutual strategic decision-making. The relationships between the players within this inner circle feature flat hierarchies and a balance of power. There is no single governing entity within the Spitex-Blu network. Instead, it is governed by a subgroup of its participants (shared governance).

The Spitex-Indigo network contains approximately 70 organizations (network size $=70$ partners) and was created as a result of a merger between two intermunicipality consortia that provided services to different geographical areas (geographical dispersion). As shown in a previous paper (Cristofoli et al. 2011a, b), Spitex-Indigo is governed by two subgroups which are responsible for providing Spitex services in two different areas. Therefore, it has a fragmented and horizontal structure. There is a balance of power between the players within these two subgroups, which basically mutually define the strategy of the network and the operational activities (shared governance).

The next network analysed in this study is the Spitex-Violet network. Homecare assistance in the city of Violet was originally provided by more than 40 organizations operating on a district level (geographical concentration), but during the 1990s the Violet municipality issued a law that forced the Spitexes to merge. In the end, only two non-profit associations and one foundation survived. These Spitexes provide homecare assistance in different districts of the city of Violet and operate in a highly integrated way under the direction and control of Violet city council. They work together to make joint strategic decisions, define operating procedures for service provision and manage joint units offering specific services (e.g. night-time services, preventive counselling and palliative care services) for the local community. This approach allows major network partners (i.e. the city, the two associations and the foundation) to build a strong and cohesive subgroup with overlapping links. The responsibility for governing the network is shared equally 
among the partners (shared governance). On top of this, the two non-profit associations and the foundation can get other non-profit organizations to provide complementary services whenever it is necessary, thus resulting in a relatively small network with approximately 13 partners (network size: 13 partners).

Finally, the Spitex-Grey network is built around a non-profit association which provides health and social care services to four municipalities from two Cantons. The Cantons gave the municipalities the responsibility for organizing the provision of health and social care services at home. Consequently, the municipalities turned to a number of associations to provide the services. Spitex-Grey evolved through mergers between five different Spitex organizations operating in four municipalities (geographical dispersion). Nowadays, the network has approximately 16 network partners (network size $=16$ partners). The most central network partner mutually coordinate activities on a strategic level by deliberating and coordinating the interests of the network members (shared governance).

\subsection{Network performance}

We used a network's ability to achieve its expected goals as a measure of network performance (Provan and Milward 2001).

On the basis of the public assignment of Spitex networks, the federal Spitex Association formulated guiding principles for every Spitex network in Switzerland. Spitex networks are asked to treat as many patients as possible, for as long as is medically possible, in familiar surroundings in order to support and preserve their autonomy and self-determination by inducing self-help (Spitex-Association 2011).

Building on this, we will take the ratio between the patients served in the year 2010 and the population in the specific Spitex network area during the same year as a performance indicator. The higher the ratio is, the greater the ability of the network will be to achieve its expected results. The more patients are served, in fact, the fewer people will be treated in nursing homes, hospitals and other stationary facilities, and this is directly related to the abovementioned guiding principles and objectives.

The data about the patients served in 2010 were taken from the annual reports of each Spitex-organization, while the data about the populations in each community in 2010 were based on the information about the residential population in Swiss municipalities provided by the Swiss Federal Statistical Office. Table 2 shows the performance of each case selected for analysis.

Table 2 Spitex network performance

\begin{tabular}{ll}
\hline Case & Performance (\%) \\
\hline Spitex-Blu & 1.2 \\
Spitex-Indigo & 3.4 \\
Spitex-Violet & 2.9 \\
Spitex-Grey & 2.2 \\
Swiss average & 2.8 \\
\hline
\end{tabular}


As revealed by Table 2 , the performances vary significantly from network to network. They go from $1.2 \%$ in the case of the Blu network to $3.4 \%$ for the Indigo network. As mentioned above, the Swiss average is $2.8 \%$, (Swiss Federal Statistical Office 2010), so we can say that two of the networks put in a below-average performance and two networks were above average. While Spitex-Blu (1.2\%) and Spitex-Grey (2.2\%) displayed a below-average performance, the Spitex-Violet $(2.9 \%)$ and Spitex-Indigo networks (3.4\%) outstripped the average performance in Switzerland.

\subsection{Data collection and analysis}

To ensure that the qualitative analysis was reliable (Denzin 1978; Denzin and Lincoln 1994), different data source and data collection mechanisms were triangulated. Firstly, we collected data through official documents that were provided by governments. Secondly, after getting a broad insight into each case, a questionnaire was given either to the Spitex CEO or, if this person was not available, to a person working in the management team. The aim of the questionnaire was to collect information about all of the players involved, their methods, quality and intensity of collaboration, and the functioning procedures within the networks and the network management. Thirdly, semi-structured interviews with the key players in the Spitex networks were conducted. They were based on the knowledge already acquired thanks to the documentary analysis and the questionnaire. The interviews allowed further investigation of aspects emerging from the first two steps and made it possible to gain in-depth knowledge of every single network. The interviews were conducted either directly at the Spitexorganization or by telephone and they were transcribed no more than $24 \mathrm{~h}$ after each conversation. In total, there were 25 interviews with key players.

The data were analysed following the three steps of data description, analysis and interpretation (Miles and Huberman 1994). At the end of the process, relationships showing the joint impact of the network coordination mechanisms and the abilities of the network manager on network performance were explored.

\section{Findings}

Table 3 shows the results of the case study analysis.

As far as coordination mechanisms are concerned, the networks analysed share some similarities while also presenting important differences. There was no mention of informal relationships between people that could be found in all four cases, while the reliance of the four networks on formalized coordination mechanisms also differed significantly.

In the case of Spitex-Blu, the network partners do not rely on formalized rules to increase the liability for any decisions that are made. According to the CEO, "the task group mentioned is responsible for defining the network's goals and the operational activities used to achieve these goals. However, so far we have worked without any formal agreements." In addition, she mentioned that the reliance on 
Table 3 Results of the case study analysis

\begin{tabular}{|c|c|c|c|c|}
\hline & Spitex-Blu & $\begin{array}{l}\text { Spitex- } \\
\text { Indigo }\end{array}$ & Spitex-Violet & $\begin{array}{l}\text { Spitex- } \\
\text { Grey }\end{array}$ \\
\hline Governance form & Shared & Shared & Shared & Shared \\
\hline Network size & Larger & Larger & Smaller & Smaller \\
\hline Geographical concentration & Concentration & Dispersion & Concentration & Dispersion \\
\hline $\begin{array}{l}\text { Reliance on formalized coordination } \\
\text { mechanisms }\end{array}$ & No & Yes & Yes & Yes \\
\hline Presence of a distinct network manager & No & No & No & No \\
\hline Presence of network administrators & Yes & Yes & Yes & No \\
\hline Network performance & Lower & Higher & Higher & Lower \\
\hline
\end{tabular}

formalized rules and mechanisms is very low due to the fact that network meetings were only introduced recently and formalized network rules had yet to be established, but the most important players are working on institutionalizing and formalizing network relationships.

The coordination systems in the other three networks seem to place more of an emphasis on formalized network rules, contractual agreements and well-organized network meetings.

The Spitex-Indigo network relies on formalization to a great extent. Decisions are always made during the general meeting or by the executive committee, "as required by law and established in the statute" (as quoted in the previous paper). Therefore, the decision-making process is strictly based on formalized rules. Furthermore, meetings at all levels of the network are scheduled and well-planned. Meanwhile, the relationships between the different network partners are defined by contractual agreements. Accordingly, the relationships between the two subgroups are regulated by a contract which defines their links and their managerial autonomy.

Similarly, the Spitex-Violet network relies on formalized mechanisms between the most important network partners in order to be able to guarantee common ground and unity in certain aspects. The running of the network by the city council and the two most important Spitex organizations is based on regular network meetings (six to seven a year), joint decision-making, and contracts defining joint strategic and operative activities, with the contribution of every player in the governing subgroup. The CEO of one of the two Spitexes mentioned "monthly meetings with the other non-profit Spitex and regular meetings with the city council and the foundation, as well as regular meetings with our partners, hospitals and health insurance firms. Doodle is used to set the dates of the meetings." There are also formal contracts with partner organizations that provide complementary services, and the various players rely on them a great deal. According to the CEO of one partner organization, "the collaboration is based on a contract known as a 'performance agreement' and there are meetings two or three times a year."

The Grey network relies on formalization to a great extent, as well, and there are contractual agreements between the key players. The CEO of the Spitex organization stated that "contracts are very important for the collaboration between the Spitex, the 
municipalities, the Cantons and other non-profit organizations which provide complementary services." These contracts shape the responsibilities and activities of each member, as well as the relationships between different members. "We have contracts which lay down our competences and responsibilities. These contracts outline our responsibilities and those of partner XY, and we have to comply with them." (Spitex-Grey CEO). Furthermore, the meetings for joint decision-making by partner organizations are well-planned and take place on a regular basis (five times a year). During these meetings, the content of agreements is discussed and can be altered if necessary: "they (the contracts) have to be adjusted once in a while". It is possible to conclude that there is a high degree of formalization within the network and that formalized network rules are important for network activities on a strategic level.

We were also able to find some similarities and differences in the four cases in terms of the abilities of the network manager.

The most notable feature of the Spitex-Blu network in this respect is that the management is left to a widespread group of institutional bodies from different organizations, which currently maintain the existing rules and procedures, ensure that the players comply with them and therefore facilitate interaction between partners. According to the Spitex CEO in fact "It is a responsibility of the official bodies of the network partners to discuss strategic goals and increase commitment".

The situation in Spitex-Indigo is quite similar. Any disputes among partners are usually resolved by the governing bodies (the executive committee or general meeting), without input from the director's office. As the director said, "there was some tension among network partners about the possibility of providing services to children and poor people as well, but that was a matter for politicians rather than an issue for the director" (as quoted in a previous paper). Furthermore, there is no specific figure who is able to facilitate interaction between partners, unify interests or build up the commitment of network members. Everything is coordinated and discussed in the general and executive committee meetings. Therefore, no clear network manager could be identified. However, many interviewees identified the general director, the president and the vice-president of the committee as the main characters involved in the "administration" of the network.

Just as the responsibility for governing the network is shared equally among three major network partners in the Spitex-Violet network, there are three main members who seek to promote interaction between the partners and the smooth running of the network (the city council and the governing bodies of the two Spitex organizations). These players-which at the same time constitute the core of the governing subgroups-endeavour to unify interests, ease tensions, and facilitate collaboration among network partners. Conflicts are solved by political decisions and interests are only unified when they are in line with organizational interests. Furthermore, the city council strives to facilitate collaboration within the inner circle of major partner organizations, but the success of this mission is dependent on the willingness of each organization. Consequently, there is no unified network management structure in the Spitex-Violet network. The following statement by the CEO of one Spitex organization sums up the situation among the major network members very well: "The two Spitex governing bodies and the city council form the core strategic decision-making group in the network. At this level, every partner has a certain 
influence and can bring up its own ideas about future strategic development." Similarly, according to a worker at a Spitex partner: "The CEO and the board can work together to define and redefine the objectives and strategic goals for homecare provision."

Spitex-Grey seems to be the only case in which there is neither a person managing the network, nor an institutional body acting in compliance with the existing rules and formal agreements. "There is no member of the network that coordinates or manages the activities of the different organizations," stated the Spitex CEO. "Everything is managed on a strictly contractual basis."

\section{Discussion and conclusion}

The cross-case analysis allows us to give some answers regarding the central research issue: "How to be successful in shared-governance networks".

Despite their size and geographical concentration, we were able to identify a pattern of factors behind the high performance levels achieved by the two successful public networks, namely Spitex-Indigo (3.4\%) and Spitex-Violet (2.9\%). These shared-governance networks both rely on a well-defined and formalized package of coordination mechanisms and the simultaneous presence of a group of institutional bodies to administer them (network administrators). In contrast, the Spitex-Blu $(1.2 \%)$ and Spitex-Grey $(2.2 \%)$ networks lack either a reliance on formalized package of coordination mechanisms or network managers/administrators who can govern the interaction between the partners in accordance with the existing rules and procedures.

On the basis of this, it seems possible to argue that the success of sharedgovernance networks is ensured by the combination of reliance on formalized coordination mechanisms and the presence of network administrators (Fig. 2). In this context, we can theoretically propose that in order to be successful, the more decentralized a network is, and the more stakeholders there are in the decisionmaking processes, the more the network should rely on a well-defined and formalized package of coordination mechanisms that are implemented by a pool of network administrators.

We are thus able to make some contributions to public network literature.

Firstly, the results of our study follow the direction suggested by Kenis and Provan (2009), with exploration of network success in relation to different

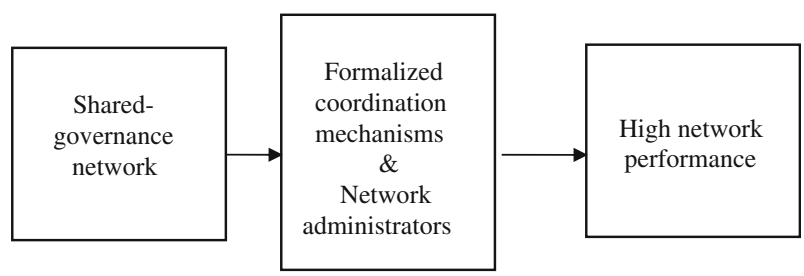

Fig. 2 How to be successful in shared-governance networks 
governance structures. In particular, by focusing on shared-governance networks, our work complements the existing studies and shows that network success is not only affected by the size and geographical concentration of the network. Management does matter. The reliance on mechanisms to coordinate partner interaction and the presence of institutional bodies to guarantee compliance with the existing rules and procedures seems to lead to success, regardless of the conditions identified by previous studies.

Secondly, the results of our study follow the directions suggested by Turrini et al. (2010), with exploration of the interdependence of predictors of network performance. Coordination mechanisms and the abilities of the network manager (or rather of the network administrators) seem to have a joint impact with the network structure on network performance. In particular, coordination mechanisms seem to mediate the relations between shared governance and network performance. Regardless of the network size and geographical concentration, the key to network success seems to be a combination of reliance on formalized coordination mechanisms and the presence of network administrators. Our paper complements the results of our previous paper. While the previous paper made us more confident of the existence of a relationship between the network structure, mechanisms and management in jointly affecting network success, the current paper allows us to suppose that a joint impact is made by coordination mechanisms and network management (at least in shared-governance networks).

Thirdly, the results of the study have examined in greater depth and enriched the existing literature on the roles and abilities of network managers. The function of making partner interaction work-which involves various institutional bodiescannot be subsumed under the network manager approaches described in the literature review. It seems that besides the already well-defined managerial approaches of "facilitator", "mediator" and "leader" (Agranoff and McGuire 2001, 2003; McGuire 2002), there is another approach that is often necessary when running public networks. We will label it "the network administrator(s)". In particular, the network administrator(s) can be defined as a group of institutional bodies which are usually representatives of different organizations. Just like bureaucrats, they maintain well-defined and formalized coordination mechanisms as a basis for a procedural decision-making and operating processes. These network administrators normally follow impersonal, legislated decision-making procedures so as to preserve a balance of power between the major network partners and thus give guaranteed stability, accountability and goal attainment in environments characterized by the presence of various important network partners.

Fourthly, successful shared-governance networks tend to take a more bureaucratic approach in order to ensure power-sharing and govern the network according to established rules and procedures. Thereby, the scope for unilateral managerial intervention is reduced to a minimum, while the reliance on well-defined and formalized coordination instruments and mechanisms (such as formalized network rules, contractual agreements, or well-organized network meetings) becomes a governing principle. The establishment and maintenance of these coordination instruments and mechanisms and the establishment of power-sharing within the network are the main purposes of the network administrators. The results of our 
study raised the never-ending issue of the bureaucratization of public networks. As described by Bardach (1998), in order to work effectively, shared-governance networks seem to need a number of features normally associated with hierarchical organizations. Among them is formalization.

From a managerial point of view, the results of our study seem to provide those involved in shared-governance networks with some suggestions about how to make them work: the greater the complexity and involvement of multiple players in network governance, the more preferable it is to comply with the existing rules and procedures for partner interaction.

This study is a preliminary step in a wider research project that aims to explore the joint effects of the predictors of network performance on network success. It provides us with helpful insights, but it requires further development.

First of all, a quantitative study employing statistical techniques could be a useful way of testing the proposition. This is the aim of our wider research project.

Secondly, the concept of network performance may need further work and it might be appropriate to create a composite index that takes its multidimensionality into account. In particular, in mandatory networks involving public and non-profit organizations that are labour- and skill/knowledge-intensive like Spitex networks, it may be useful to examine client wellbeing as compared to measurements such as QALY (quality-adjusted life years) or quality of daily living.

Thirdly, further insights could come from considering the networks for the provision of health and social services as professional networks. In this case, coordination mechanisms, project management systems and managerial mechanisms need to be customized in accordance with the specific demands of labour- and skill-intensive organizations.

Acknowledgments This article is part of a research project (no. 127512/1) financed by the Swiss National Science Foundation (http://www.snf.ch) and supported by the Swiss Public Administration Network (SPAN) (www.swipan.ch). We would also like to thank all the people that accepted to participate in our study.

\section{References}

Agranoff, R., \& McGuire, M. (1998). Multinetwork management: Collaboration and the hollow state in local economic policy. Journal of Public Administration Research and Theory, 8(1), 67-91.

Agranoff, R., \& McGuire, M. (2001). After the network is formed. Process, power and performance. In M. Mandell (Ed.), Getting results through collaboration networks and network structures for public policy and management (pp. 11-29). Westport, CT: Quorum Books.

Agranoff, R., \& McGuire, M. (2003). Collaborative public management: New strategies for local governments. Washington, DC: Georgetown University Press.

Bardach, E. (1998). Getting agencies to work together. The practice and theory of managerial craftsmanship. Washington DC: Brookings Institution Press.

Bazzoli, G. J., Casey, E., Alexander, J. A., Conrad, D. A., Shortell, S. M., Sofaer, S., et al. (2003). Collaborative initiatives: Where the rubber meets the road in community partnerships. Medical Care Research and Review, 60(4), 63-94.

Conrad, D. A., Cave, S. H., Lucas, M., Harville, J., Shortell, S. M., Bazzoli, G. J., et al. (2003). Community care networks: Linking vision to outcomes for community health improvements. Medical Care Research, 60(4), 95-129. 
Cristofoli, D., Maccio' L., \& Sancino, A. (2011a). Managing successful networks: The case of intermunicipality collaboration in Switzerland. Bern: Yearbook Swiss Public Administration Society.

Cristofoli, D., Maccio L., \& Pedrazzi L. (2011b). Structure, mechanisms and management in succesfull networks. Paper presented at the XV IRSPM conference, 11-13 April, 2011, Dublin.

Cristofoli D., Maccio' L., \& Markovic J. (2012). Una, nessuna, centomila” recipes for a good network performance. Paper presented at the XVI IRSPM Conference, 11-13 April, 2012, Rome.

Denzin, N. K. (1978). The research act. Englewood cliffs: Prentice Hall, 2a ed.

Denzin, N. K., \& Lincoln, Y. S. (1994). Introduction. Entering the field of qualitative research. In N. K. Denzin, \& Y. S. Lincoln (Eds.), Handbook of qualitative research, Thousand Oaks: Sage.

Ferlie, E., \& Pettigrew, A. (1996). Managing through networks: Some issues and implications for the NHS. British Journal of Management, 7(March), 81-99.

Gray, B. (1989). Collaborating: Finding common ground for multiparty problems. San Francisco: JosseyBass.

Huang, K., \& Provan, K. G. (2007). Structural embeddedness and organizational social outcomes in a centrally governed mental health services network. Public Management Review, 9(2), 169-189.

Jennings, E. T., \& Ewalt, J. A. (1998). Interorganizational coordination, administrative consolidation and policy performance. Public Administration Review, 58(5), 413-421.

Kenis, P., \& Provan, K. G. (2009). Towards an exogenous theory of public network performance. Public Administration, 87(3), 440-456.

Kickert, W. J. M., Klijn, E. H., \& Koppenjan, J. F. M. (Eds.) (1997). Managing complex networks. London: Sage.

Kljin, E. H. (1996). Analyzing and managing policy processes in complex networks: A theoretical examination of the concept policy network and its problems. Administration \& Society, 28(1), 90-120.

Kort, M., \& Klijn, E. H. (2011). Public-private partnerships in urban regeneration projects: Organizational form or managerial capacity? Public Administration Review, 71(4), 618-626.

Mandell, M. P. (Ed.). (2001). Getting results through collaboration networks and network structures for public policy and management. Westport, CT: Quorum Books.

McGuire, M. (2002). Managing networks: Propositions on what managers do and why they do it. Public Administration Review, 62(5), 599-609.

Meier, K. J., \& O'Toole, L. J. (2001). Managerial strategies and behaviour in networks: a model with evidence from U.S. public education. Journal of Public Administration Research and Theory, 11(3), 271-293.

Miles, M. B., \& Huberman, A. M. (1994). Qualitative data analysis. Beverly Hills: Sage.

Mitchell, S. N., \& Shortell, S. M. (2000). The governance and management of effective community health partnerships: A typology for research, policy and practice. The Milbank Quarterly, 78(2), 241-289.

Mitchell, R. E., Florin, P., \& Stevenson, P. E. (2002). Supporting community-based prevention and health promotion initiatives: Developing effective technical assistance systems. Health Education and Behavior, 29(5), 620-639.

O’Toole, L. J., \& Meier, K. J. (2004). Public management in intergovernmental networks: Matching structural networks and managerial networking. Journal of Public Administration Research and Theory, 14(4), 469-494.

Provan, K. G., \& Kenis, P. (2008). Modes of network governance: Structure, management and effectiveness. Journal of Public Administration Research and Theory, 18(2), 229-252.

Provan, K. G., \& Milward, B. H. (1995). A preliminary Theory of interorganizational network effectiveness. Administrative Science Quarterly, 40(1), 1-33.

Provan, K. G., \& Milward, B. H. (2001). Do networks really work? A framework for evaluating public sector organizational networks. Public Administration Review, 61(4), 414-423.

Provan, K. G., \& Sebastian, J. G. (1998). Networks within networks: Service link overlap, organizational cliques, and network effectiveness. Academy of Management Journal, 41(4), 453-463.

Provan, K. G., Veazie, M. A., Staten, L. K., \& Teufel-Shone, N. I. (2005). The use of network analysis to strengthen community partnerships. Public Administration Review, 65(5), 603-613.

Shortell, S. M., Zukoski, A. P., Alexander, J. A., Bazzoli, G. J., Conrad, D. A., Hasnain-Wynia, R., et al. (2002). Evaluating partnerships for community health improvement: Tracking the footprints. Journal of Health Politics, Policy and Law, 27(1), 49-91.

Spitex-Association. (2011). Das ist Spitex. Website, http://www.spitex.ch/index.cfm/CFAD1211-C8F46C92-5B52FD8119D11097/, 9.12.2011. 
Steiner, R. (2000). New public management in Swiss municipalities. International Public Management Journal, 3, 169-189.

Steiner, R. (2003). The causes, spread and effects of intermunicipal cooperation and municipal mergers in Switzerland. Public Management Review, 5(4), 551-571.

Swiss Federal Statistical Office. (2010). 'Spitex-Statistik 2009. Online-publication http://www.bfs.admin. $\mathrm{ch} / \mathrm{bfs} / \mathrm{portal} / \mathrm{de} /$ index/themen/14/22/publ.html?publicationID=4204), 9.12.2011.

Turrini, A., Cristofoli, D., Frosini, F., \& Nasi, G. (2010). Networking literature about determinants of network effectiveness. Public Administration, 88(2), 528-555.

Yin, R. K. (1984). Case study research: Design and methods. Beverly Hills, CA: Sage.

\section{Author Biographies}

Prof. Daniela Cristofoli is SPAN Assistant Professor in Public Management at the Università della Svizzera Italiana. Her research interests include public network management and governance, public management reforms and human resource management in the public sector.

Josip Markovic is a PhD Candidate in Public Management at the Università della Svizzera Italiana. His main research interest is the effect of contextual, structural and managerial factors on public network performance. At the same time he works on developing an understanding of forms of public network governance in varying circumstances.

Prof. Marco Meneguzzo is full professor of Public administration and management at the Department of Business, Government and Philosophy at the University of Rome Tor Vergata and professor of Public and non-profit management at the Università della Svizzera Italiana. His research interests focus on the public sector and include Strategic management, innovation and change management, new public management and public governance, financial management and public-private partnerships, arts and cultural management, sustainable communities governance, health care management, social entrepreneurship and corporate social responsibility. 